lost of side effects. The purpose of this study was to investigate the type and incidence of skeletal abnormalities in bodybuilders. Situational abnormality of 118 bodybuilders were assessed via posture screen and inserted in examination form. $\chi^{2}$ Test was used to analyse the data. Results of this study showed that in total 874 situational deformities was observed in the athletes. The average deformity in each athlete was nearly 7.5. The most common abnormalities were medial rotated shoulder $(10.4 \%)$, lordosis $(9.61 \%)$, anterior head tilt (8.65\%) and kyphosis $(7.78 \%)$. There was a significant different among trunk and head abnormalities with upper extremities abnormalities $\left(\chi^{2}=\right.$ 12.28, $\mathrm{p}<0.01)$ and lower extremities abnormalities $\left(\chi^{2}=4.17\right.$, $\mathrm{p}<0.05)$. There was no significant difference between abnormalities of lower extremities and upper extremities $\left(\chi^{2}=2.14\right.$, $\mathrm{p}<0.05)$. It can be concluded that the incidence of abnormalities among bodybuilders is very high. Further studies may deal with the causes of these abnormalities. This is a warning to these athletes. So, trainers should reduce the athlete's abnormalities with designing standard training programme.

\title{
111 THE PROFILE OF BODY ABNORMALITIES OF BODYBUILDERS
}

Mahdi Rostami Haji-Abadi, Nader Rahnama Faculty of Physical Education and Sport Sciences, University of Isfahan, Isfahan, Iran

10.1136/bjsm.2010.078725.111

Situational abnormalities usually occur due to the non-standard use of body which leads in the deformity of body and has 